\title{
JUURNAL.RU
}

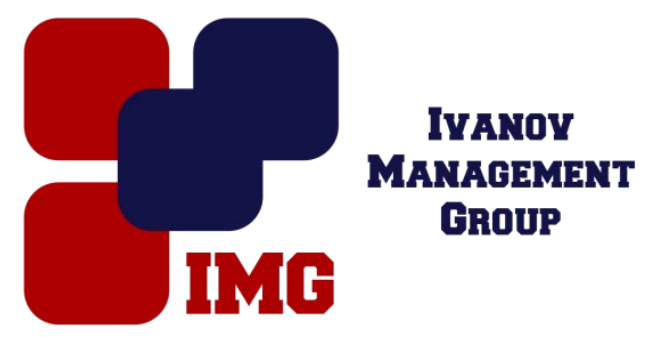

Каримов Т.P. Казанский Государственный Аграрный Университет Казань, Россия

doi: 10.18411/lj-31-10-2016-3-05

idsp 000001:lj-31-10-2016-3-05

\section{Эффективность управления инновационной деятельностью нефтеперерабатывающего предприятия}

Динамические события произошедшие в финансовой и экономических плоскостях рыночного пространства Российской Федерации за последние два года негативным образом отразились практически на всех функционирующих там субъектах, включая предприятия сферы нефтепереработки (нефтеперерабатывающие предприятия).

Для нивелирования последствий сложившейся ситуации многие нефтеперерабатывающие предприятия, следуя мировым тенденциям в области антикризисного менеджмента, пытаются оптимизировать свои внутренние процессы (от производства до управления), улучшая тем самым эффективность своей деятельности $[1, \mathrm{c.5}]$.

Как отмечают именитые исследователи, профессионально консультирующие крупнейшие нефтеперерабатывающие предприятия Российской Федерации (Ernst\&Young, PKF, Инфотек-Консалт, Эксперт-РА и другие) в 2015 году одна из наиболее существенных групп проблем внутреннего характера относилась к сфере управления [2, 3, 4].

Так, например, по данным компании Ernst\&Young существенность проблем, приходившихся на сферу управления в обозначенном секторе экономики в 2015 году достигала 34,59\% из 100 возможных [3].

Формализуя обозначенный тезис на основе анализа некоторых выдержек аналитических материалов исследований, указанных выше 
профессиональными консультантами, была получены авторская диаграмма о удельном распределении количества проблем относительно их общего числа, приходившихся на различные элементы сферы управления ведущими нефтеперерабатывающими предприятиями Российской Федерации в первой половине 2016 года (рис. 1).
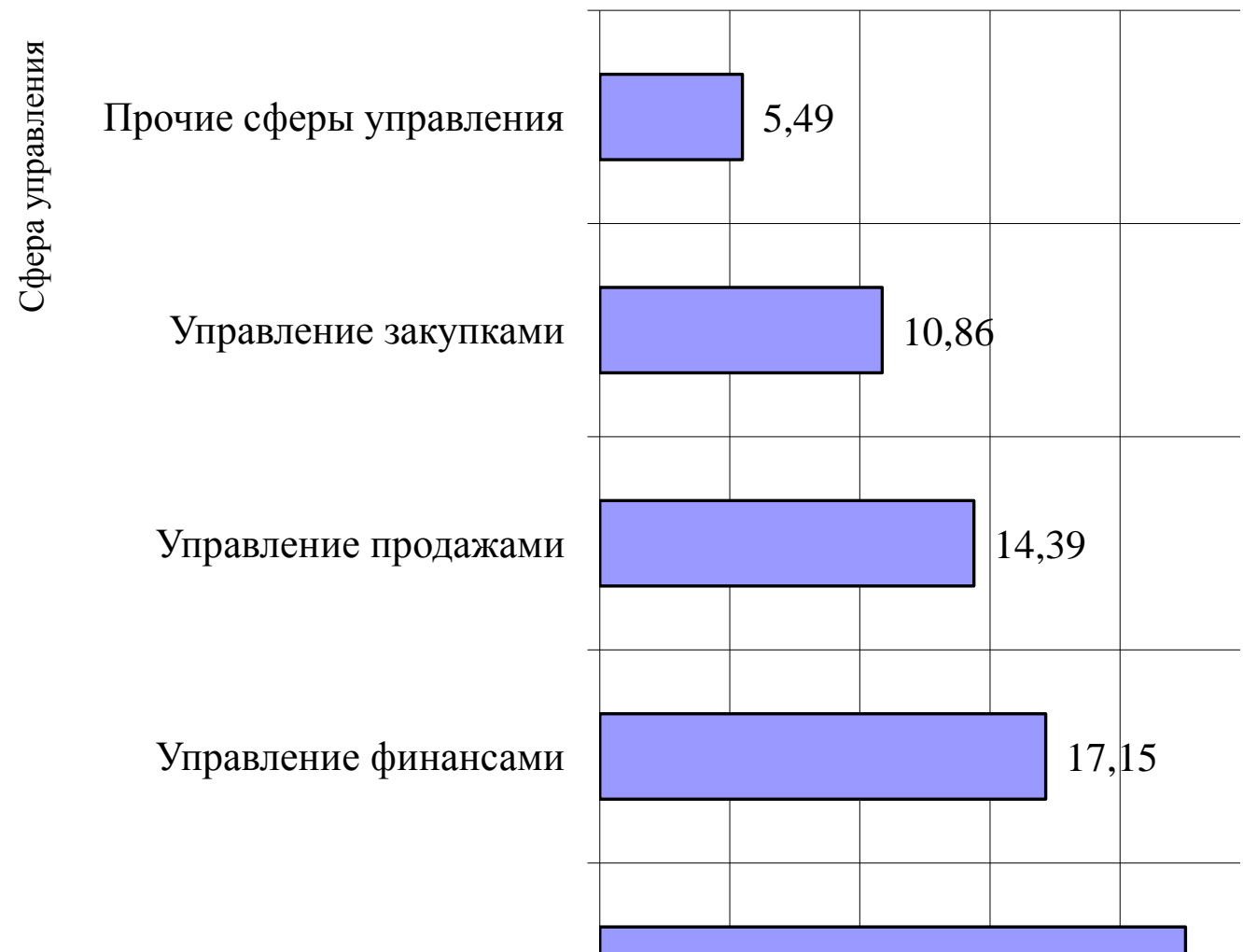

Управление инновациями

Управление финансами

Управление продажами

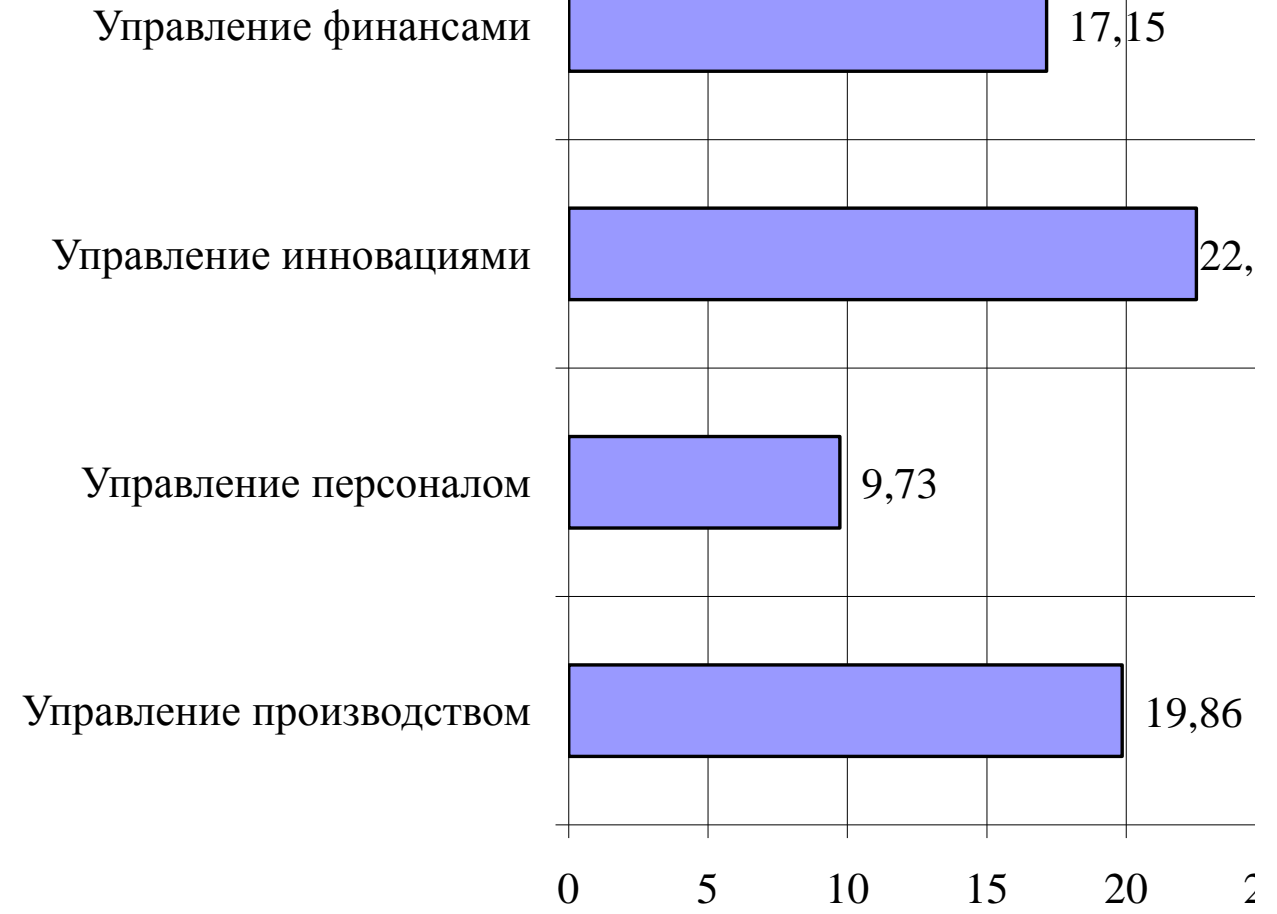

Рис. 1. Авторская диаграмма удельного распределения количества проблем относительно их общего числа, приходившихся на различные элементы сферы управления ведущими нефтеперерабатывающими предприятиями Российской Федерации, 2016 г. (1-2 кварталы) 
Примечание: приведенное на рисунке 1 распределение детализировало лишь проблематику сферы управления ведущих нефтеперерабатывающих предприятий Российской Федерации (ее доля здесь была принята за 100\%).

Как можно увидеть из рисунка 1 удельное распределение количества проблем относительно их общего числа, приходившихся на различные элементы сферы управления ведущими нефтеперерабатывающими предприятиями Российской Федерации в 2016 году носило неоднородный характер.

Так, наиболее существенными (доля проблем от $15 \%$ и выше) проблемными сегментами здесь выступили:

- управление инновациями (доля проблем порядка 22,52\% из 100\%);

- управление производством (доля проблем порядка 19,86\% из 100\%);

- управление финансами (доля проблем порядка 17,15\% из 100\%).

- Промежуточное положение (доля проблем от 10 до $15 \%$ включительно) заняли такие сегменты, как:

- управление продажами (доля проблем порядка 14,39\% из 100\%);

- управление закупками (доля проблем порядка 10,86\% из 100\%);

- Завершали исследуемое распределение:

- сфера управления персоналом (доля проблем порядка 9,73\% из 100\%);

- прочие сферы управления (доля проблем порядка 5,49\% из 100\%).

Исходя из того, что большее количество проблем в управлении нефтеперерабатывающими предприятия Российской Федерации приходилось на сферу инноваций, был составлен динамический рейтинг эффективности данного процесса (рис. 2).

По рисунку 2 поясню, что под эффективностью управления инновациями в данном исследовании понималось достижение фактических значений ключевых показателей эффективности относительно плановых величин по инновационным проектам, реализуемым в нефтеперерабатывающих предприятиях в периоды проведения исследования.

Отмечу, что периодами проведенного исследования стали 2010-2016 годы (усредненные значения), а механизмом получения оценок - результаты опроса целевой группы квалифицированных экспертов. 


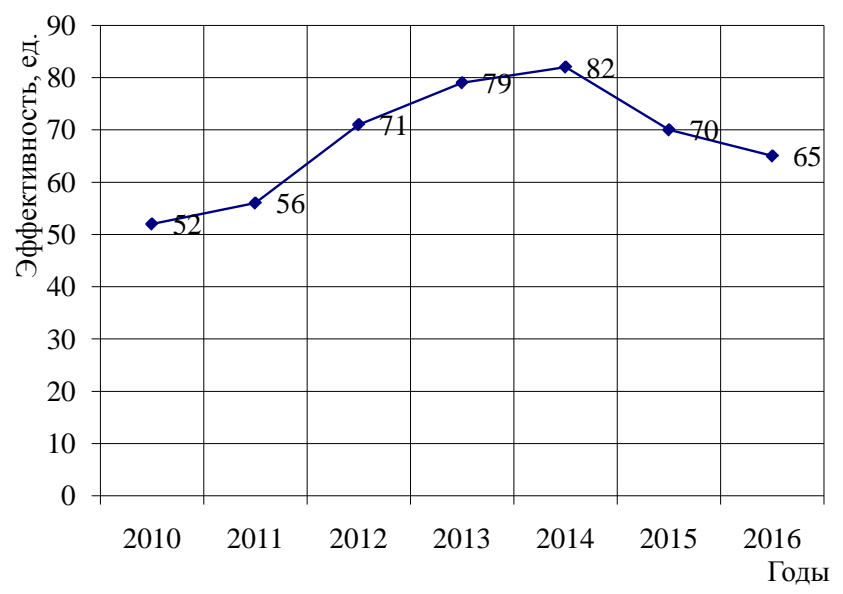

Рис. 2. Динамический рейтинг эффективности управления инновациями в нефтеперерабатывающих предприятиях Российской Федерации за 2010-2016 годы (ед.)

Единицей измерения рейтинга стало предложенное экспертами «рейтинговое число», измеряющееся в целых единицах от 1 до 100 включительно, где:

- 0 - минимальное значение рейтинга эффективности управления инновациями в нефтеперерабатывающих предприятиях Российской Федерации (наихудший вариант);

- 100 - максимальное значение рейтинга эффективности управления инновациями в нефтеперерабатывающих предприятиях Российской Федерации (наилучший вариант).

Значение рейтинга за 2016 год носило прогнозный характер с уровнем достоверности результата прогноза в 98,56\%.

Как можно увидеть - данные составленного рейтинга однозначно свидетельствуют о снижении исследуемого показателя на протяжении 2014 2016 годов более чем на 15 единиц, приближаясь к средним значениям 20112012 годов.

Таким образом можно сделать вывод, что нефтеперерабатывающим предприятиям Российской Федерации в 2016 году на фоне снижения эффективности управления инновациями, следует обратить особое внимание не 
только на определяющие внутренние процессы, но и на все без исключения проекты инновационного характера, реализуемые в текущей и стратегической перспективе.

\section{Литература}

1. Абрамов, О. В. Основные принципы эффективной организации процесса стратегического управления корпорацией / О. В. Абрамова// Вестник СГЭУ, 2013, 1. - С. 5-8.

2. Каримов, Т. Р. К вопросу управления стимулированием инновационной деятельности в нефтеперерабатывающей отрасли России / Т. Р. Каримов // Актуальные проблемы экономики и права. - 2012. - 2 (22). - С. 40 - 48.

3. Компания Ernst\&Young [Электронный pecypc] : Аналитические материалы. - Официальный сайт компании Ernst \& Young, 2016. - Режим доступа: http:// www.ey.com/

4. Компания ООО «ИнфоТЭК-КОНСАЛТ» [Электронный ресурс]: Аналитические материалы. - Официальный сайт компании ООО «ИнфоТЭК-КОНСАЛТ», 2016. - Режим доступа: http://www.citek.ru/ 